\title{
LA RELACIÓN ENTRE LA DOCUMENTACIÓN NARRATIVA DE EXPERIENCIAS PEDAGÓGICAS Y EL OCIO FORMATIVO DE DOCENTES JUBILADOS
}

\author{
A RELAÇÃO ENTRE A DOCUMENTAÇÃO NARRATIVA DE \\ EXPERIÊNCIAS PEDAGÓGICAS E O ÓCIO FORMATIVO DE \\ DOCENTES APOSENTADOS
}

\section{THE RELATIONSHIP BETWEEN THE NARRATIVE DOCUMENTATION OF PEDAGOGICAL EXPERIENCES AND THE FORMATIVE LEISURE OF RETIRED TEACHERS}

\author{
Danise Grangeiro* \\ Investigadora da Faculdade de Filosofia e Letras da Universidade de Buenos Aires
}

(UBA)

Resumen: El artículo pretende descubrir cómo la documentación narrativa de experiencias pedagógicas puede contribuir con el ocio de los docentes jubilados. Reflexionar sobre estos temas es un ejercicio útil para comprender las consecuencias causadas por la ausencia del trabajo y el bien estar que puede ser generado por la escrita y por el repensar de sus experiencias pedagógicas. Este movimiento de escritura y donación de sus narrativas a nuestra sociedad - especialmente a los docentes en formación posibilitó promover la política de la inclusión (FREIRE, 1970), la política de la felicidad, del reconocimiento de los derechos humanos y de los adultos mayores.

Palabras clave: Docentes jubilados. Ocio. Saber experiencial. Documentación narrativa de experiencias pedagógicas.

\footnotetext{
* Doctora en Ciencias de la Educación. Investigadora de la Universidad de Buenos Aires- UBA; Maestría en Psicología por la Universidad de Fortaleza.
} 
Resumo: O artigo pretende descobrir como a documentação narrativa de experiências pedagógicas pode contribuir com o ócio dos docentes aposentados. Reflexionar sobre estes temas é um exercicio útil para compreender as consequências causadas pela ausência de trabalho e o bem-estar que pode ser proporcionado pela escrita e pelo repensar suas experiências pedagógicas. Este movimento de escrita e doação das suas narrativas à nossa sociedade - especialmente aos docentes em formação possibilitou promover a política de inclusão (FREIRE, 1970), a política da felicidade, do reconhecimento dos direitos humanos e dos direitos do idoso.

Palavras-chave: Docentes aposentados. Ócio. Saber da experiência. Documentação narrativa de experiências pedagógicas.

Abstract: The article aims to discover how the narrative documentation of pedagogical experiences may contribute to the retired teachers' leisure. Thinking about these issues is a useful exercise to understand the effects caused by the lack of work and the well being that might be provided by writing and reflecting their pedagogical experience. This movement of writing and donating their narratives to the society - specially to the under graduated teachers- aimed to promote the political inclusion (FREIRE, 1970), the politics of happiness, the recognition of the laws of the human and elderly rights.

Keywords: Retired teachers. Leisure. Experience knowledge, Narrative Documentation of Pedagogical Experiences.

\section{INTRODUCCIÓN}

Con la creciente expectativa de vida, la tercera edad ya no es parte de la última etapa del desarrollo humano. Ahora no es extraño que las personas transiten la cuarta edad. Una gran parte de los adultos con menos de 85 años aún se siente joven, tiene salud y capacidad para continuar activo. Muchos no desean dejar de trabajar y, al jubilarse, les gustaría encontrar otra actividad que ocupe el lugar del trabajo. Beauvoir (1970) llama a este fenómeno "la paradoja de nuestra época" porque las personas gozan de mejor salud que en otras épocas, tienen sabiduría y sed de conocimiento, pero deben hacer frente al tiempo libre y el vacío de la jubilación. En este proceso, aparece todo el peso del retiro y toda la necesidad de una reestructuración del tiempo libre. Es justo en el encuentro de la jubilación con la libertad que muchos de los jubilados se sienten presos. Otra paradoja. Surge ahí la discrepancia entre el querer hacer y el hacer. Es justo en ese gap que el adulto mayor se pierde, se silencia, se aísla y encuentra la depresión y los vicios. 
La discusión se torna más interesante al enfocarnos en los sentimientos y necesidades de los jubilados. Personas que, como cualquiera de nosotros, tienen desde el nacimiento la imposición de cumplir reglas, rutinas y horarios: tenemos hora para comer, para bañarnos, para ir al jardín, a la escuela, tenemos que producir en el mundo escolar y después producir en el mundo del trabajo. Desafortunadamente, el descanso, el ocio y el tiempo libre son palabras asociadas a la improductividad, la inutilidad, la incapacidad y la irresponsabilidad.

La investigación está basada en la realidad de los docentes jubilados y pone en cuestión el sentimiento de vacío, el silencio y la soledad por la que este grupo etario atraviesa. De esta manera, este trabajo tiende a hacer foco en las potencialidades de los talleres de documentación narrativa de experiencias pedagógicas como forma de ocio formativo de los docentes jubilados. En ellos, los docentes en jubilación se forman, se trans-forman y se co-forman a través de la escritura y del repensar sus experiencias pedagógicas.

Esta investigación propone repensar la jubilación, la formación docente y la pedagogía, como también arrojar una nueva luz sobre las investigaciones (auto) biográficas dirigidas a los adultos mayores. La investigación que hemos desarrollado junto a los docentes jubilados apunta hacia ciertos aspectos que son importantes para tener en cuenta en el desarrollo humano y social del adulto mayor. De esta manera, la investigación narrativa, el método empleado y el producto final nos ofrecen la oportunidad de mirar más profundamente su forma de ver/ser/estar en el mundo.

El presente estudio también arroja luces sobre la formación docente. Una manera interesante y fructífera de intercambiar narrativas de experiencias pedagógicas escritas por los docentes jubilados y docentes en formación fue presentada en los institutos de profesorado de la Provincia de Buenos Aires. En el intercambio de saberes experienciales y pedagógicos con otra generación, los jubilados encontraron el sentido de escribir sus narrativas pedagógicas, mientras los docentes en formación encontraron el sentido de su profesión. Escuchar a los docentes jubilados fue una forma de permitir una formación de profesores fundamentada en historias de vida (JOSSO, 2004); resultando en una formación más humana, más práctica, más significativa y menos abstracta.

\section{CRUZANDO EL PUENTE DE LA JUBILACIÓN: ENTRE LA ACTIVIDAD Y LA INACTIVIDAD}

La jubilación es uno de los problemas más complicados que debe enfrentar el adulto mayor. Con 65 años de edad muchos se sienten en condiciones de seguir 
ocupando su lugar de trabajador, se ven fuertes, capaces y experimentados. Volver al hogar y dejar la rutina no son cambios sencillos. Este momento de transición puede transformar sus vidas, sus formas de ver el mundo y las formas en que el mundo los ve a ellos. El sentimiento de inutilidad debilita al "nuevo anciano". Tienen que ser muy fuertes para lograr vencer el estereotipo que la sociedad les impone.

La palabra "jubilación" proviene del latín Uibulare, que significa "gritar de alegría". Sin embargo, lejos de ser un "grito de alegría", muchas veces la jubilación causa dolor. Dolor por la partida definitiva, por el vacío, por tener que abandonar los escenarios conocidos y dolor por el silencio.

Para quienes atraviesan esta etapa, la jubilación tiene distintos significados. Algunos encuentran el grito de alegría, para otros, en cambio, jubilarse es caminar por la inutilidad, o caminar hacia la muerte. Dejar la rutina y el trabajo suele ser una tarea ardua que introduce una discontinuidad radical y una ruptura con el pasado (BEAUVIOR, 1970). Esta ruptura puede resultar en el disfrute del descanso, del ocio y del tiempo libre. Pero también puede causar graves desventajas, como caída del nivel de vida y descalificación.

La molestia causada por la ausencia del trabajo es vivenciada principalmente por aquellos que no vivían su ocupación como una esclavitud. Esta fase del descanso, que debería ser aprovechada, acaba por causarles un grito de soledad y no de alegría, de desespero y desorientación y no de contemplación.

De acuerdo con Aquino y Martins (2007), el tiempo libre debería ser un tiempo máximo de autocondicionamiento y mínimo de heterocondicionamiento, o sea, ser constituido por el tiempo social donde el ser humano debería conducir con menor o mayor lucidez su vida personal y social. La necesidad del tiempo libre para la existencia del ocio y la no existencia del ocio en el trabajo son ideas erróneas. Es decir, puede no haber ocio en el tiempo libre ya que está asociado a la libertad, a la experiencia, a la reflexión, a la felicidad, al placer y la satisfacción, así como puede existir el ocio en el trabajo. Es justo ahí donde se encuentran la mayoría de los docentes jubilados de Quilmes investigados. Ellos disfrutaban del ocio formativo en sus prácticas cotidianas, aunque tuviesen menos tiempo libre. El error al pensar que despojándose de las obligaciones laborales encontrarían en el tiempo libre la libertad de ser quiénes son posibilitó el aparecimiento de la frustración al percibirse perdidos, no reconocidos e insatisfechos con la nueva vida. La falta de la educación para el ocio o la falta de un programa pre-jubilatorio pueden causar consecuencias severas en la vida de los jubilados.

El profesional que se jubila cruza un puente que, de un lado, tiene actividad, utilidad, producción, inteligencia, conocimientos, fuerza, capacidad y juventud; 
y, del otro, incapacidad, inutilidad, la falta de "responsabilidad", ociosidad, vejez, enfermedades y aburrimiento. En poco tiempo sus identidades cambian al verse forzados por la ley a cruzar el puente hacia la jubilación.

Desde la escuela fuimos entrenados para producir y cumplir horarios. Pasamos toda la infancia y la adolescencia así. Hasta el momento en que encontramos un empleo que nos obliga a seguir con la misma mecánica. Nuestro tiempo libre es dedicado al descanso y nuestro ocio debe existir dentro de él. Desde la Revolución Industrial, según Manuel Cuenca (2000, p. 259), el trabajo ocupó un lugar central en nuestras vidas. "Todo lo no productivo empezó a no considerarse trabajo o, en todo caso, actividades de carácter secundario, desarrollándose así un modo de entender las cosas que perdura hasta nuestros días."

Es completamente entendible que un ser humano, cuando se jubila, no esté preparado para vivir el silencio, el ocio y el tiempo libre. ¿Cómo es verse libre de las obligaciones?, ¿cómo es sentirse útil descansando en casa?, ¿cómo no sentir el peso de la culpa si no hay más horarios que cumplir ni cosas para hacer?, ¿cómo tener una relación con el ocio y el tiempo libre si siempre nos fue enseñado que no hacer nada era irresponsabilidad? La jubilación trae un cambio que necesita de apoyo psicológico y preparación.

En este sentido, concibo la docencia como una profesión que vive y trabaja en un espacio propicio para la creación de historias de vida por el hecho simple de compartir día tras día un mismo aula con el mismo grupo de personas. Hay ruidos. Hay intercambios. Hay contacto intergeneracional. La práctica docente permite trabajar con historias de vida, con grupos de diferentes edades, con personas interesadas en adquirir nuevos conocimientos. Así, el docente es estimulado a buscar novedades diariamente, ya que su profesión exige estar en contacto con la actualidad. En líneas generales, un docente se dedica a esta rutina durante treinta y cinco años, hasta que llegue el silencio de la jubilación. Hay un contraste muy severo entre los ruidos de la escuela y el silencio de la nueva vida. El vacío se torna evidente.

Uno se queda en silencio después. Lo que se queda es el silencio. Me siento sola sin el aula. (Docente jubilada de Quilmes) Cada uno ha pasado y ha dejado una contraseña, me parece que tenemos que valorarlas. Acá pasamos todos como muy anónimos. Nuestra historia se queda en los alumnos que encontramos en las calles y que nos saludan. (Docente jubilado de Quilmes) (informaciones verbales).

El silencio y el vacío causados por el tiempo libre están presentes en las narrativas escritas y orales de los docentes jubilados de Quilmes - sujetos colaboradores de esta investigación. La culpa es proveniente de la incapacidad de usar el tiempo 
libre, por no estar produciendo y por perderse en su propio espacio/tiempo. El trabajo como fuente de realización e identificación personal ya no existe. Pero de repente, la sociedad les dice que es importante aprovechar el tiempo libre, crear ocios productivos, descansar, hacer lo que les gustan. Desafortunadamente, no es una tarea fácil. ¡Es una paradoja!, ¡una contradicción a todo que nos fue enseñado a largo de la vida!

Muchos docentes jubilados, que no experienciaron el período pre-jubilatorio, que no pasaron por una preparación para vivenciar el ocio, no entienden el momento. Depresiones, suicidios, enfermedades, desesperación y vicios ocupan el lugar del ocio. Si no hay sueños, si no hay metas, si no hay vínculos, desafíos y contactos sociales, si no hay deseos y en cambio solo hay culpas, entonces es difícil encontrar razón para vivir. Y la falta de razón para estar vivo es el riesgo más grande de una jubilación. El grito de alegría puede transformarse en un grito de desesperación.

Estas reflexiones me llevan a Erik Erikson (1998) y sus explicaciones sobre las etapas de la vida y el desarrollo psicosocial humano. La última etapa, de acuerdo con el autor, se da con la confrontación de la integridad versus la desesperación. Es decir que, después de la jubilación, hay una necesidad de reflexionar sobre la propia vida. Si hubo logros, momentos felices y producción, entonces la sensación que queda es de integridad y de una vida exitosa. En cambio, si de la evaluación realizada resultan frustraciones más que éxitos, decepciones más que logros, estancamiento más que evoluciones, entonces hay una gran posibilidad de depresión y desesperación por estar más cerca del final de la vida. La ausencia del trabajo favorece la recolección de memorias y la obtención de ese feedback. Ese movimiento de volver al pasado, de acuerdo con el autor, se torna imprescindible en la vida de un adulto mayor.

Según Manuel Cuenca (2000), la reducción o la ausencia de trabajo provoca un gran vacío existencial que necesita ser llenado. Al respecto, Beauvoir (1970) dice sabiamente que el grito de alegría dura poco; que la depresión y el vacío destruyen el ocio creativo; que el riesgo de permanecer en soledad es grande en esa etapa de la vida; que es necesario estar activos, trazar metas, buscar nuevos espacios para poder permanecer vivo intelectual y físicamente; que son pocos los que se preparan para vivir el ocio; que son pocas las instituciones que cuidan de sus ex-cuidadores y que son muchos los que desearían continuar trabajando.

\section{LA EDUCACIÓN PARA EL OCIO}

Para Manuel Cuenca (2000) la única solución a la crisis que provoca la ausencia de trabajo es una educación para el ocio. Desde una postura educativa, la vida no 
debiera cifrar su objetivo supremo en "tener" sino en "ser". Así, nuestros actos podrían recuperar su condición de proyecto, de praxis, de vida que hemos de ir haciendo cada día, y ya no de algo que se nos invita a consumir como producto acabado. Para Cuenca (2006), educar al ser humano para vivir esta etapa es esencial para que el jubilado pueda ir al encuentro del ocio formativo, o sea un ocio que posibilita a las personas tomar las riendas de su propio ser y salir de sí misma para encontrar espacios de diálogo común.

La educación para el ocio (o, en este caso, educación para la jubilación) sería contradictoria respecto a la educación que recibimos en la escuela de la vida. Según el autor, ayudar a los jubilados a encontrar sentido en su nueva fase debería ser una obligación política. De hecho, hay países como España que ya incorporaron la ley del ocio en sus constituciones, reconociendo que los poderes públicos tienen la obligación de promover el bienestar de los ciudadanos de la tercera edad mediante la promoción de servicios sociales que atiendan, además de salud y vivienda, su cultura y su ocio.

La educación para la jubilación debe ayudar a corregir el desfase que se produce entre las expectativas y lo que realmente es, a reducir miedos, mitos y falsas interpretaciones acerca de ese período de vida. Debe ayudar a recuperar el sentido de los actos, a desarrollar nuevos roles que permitan seguir sintiéndose necesario, a encontrar diversión en otras cosas, a desarrollar la creatividad en un nuevo encuentro consigo mismo y con los otros. Debe ayudar, finalmente, a redescubrir el mundo y el entorno de un modo más sosegado y desprendido, abriendo la posibilidad de seguir recibiendo y seguir dando hasta el final. (CUENCA, 2000, p. 256).

Uno de los problemas más graves del tiempo libre es la discrepancia entre el querer hacer y el hacer. Hay un contraste entre la necesidad y la praxis, tal como vemos en el relato del docente jubilado de Quilmes investigado que dice:

Al principio sentí la libertad de no tener responsabilidades labo-
rales, horarios, ni presiones, solo pensaba en disfrutar del ocio
en forma creativa, hacer las cosas que había postergado durante
mi vida laboral. Pero con el transcurrir del tiempo vivencia-
ba que toda mi trayectoria docente estaba vaciada porque me
sentí como un material descartable. Tenía que encontrar otros
proyectos de vida. ¿Pero cuáles? Si siempre me gustó el trabajo
que hice. (Docente jubilada de Quilmes) (información verbal).

Muchos de los jubilados creyeron que ese era el momento ideal para hacer lo que querían y necesitaban. Buscaron el grito de alegría. Sin embargo, pasados algunos meses, descubrieron que no estaban haciendo todo lo que pensaban que iban a realizar. La falta de organización o preparación para vivir el ocio resulta en un "pasar el tiempo" con actividades de mayor accesibilidad (que desafortunadamente para la 
gran mayoría de los jubilados es mirar televisión). Por lo tanto, el sentimiento de culpa parece aumentar cuando la conciencia muestra que ese no era el plan para la jubilación. Según Cuenca (2000, p. 255), “estamos ante un problema de mentalización y de desarrollo de habilidades mínimas que hagan que la participación y la acción deseada sean posibles. Estamos, sencillamente, ante un problema directamente unido a la educación y el proceso educativo."

Cuando dejamos nuestro cargo, en el que hemos puesto mucha
vida, nos hemos dado nosotras, cuando nos jubilamos parece
como si todo eso perdera [...] yo pienso que es porque no es-
chuchamos más a nustros alumnos. Quizás la vida de muchos
alumnos fue nuestro centro. Fue realmente dar la vida en una
clase y no recitar una clase. (Docente jubilada de Quilmes). (in-
formación verbal).

Como sociedad tenemos la obligación de facilitar el encuentro del querer hacer y el hacer. Para eso, los jubilados necesitan pasar por un proceso íntimo, subjetivo y de autoconocimiento, que requiere tiempo y espacio. Vivir el tiempo libre, ser y existir dentro de él no son tareas sencillas, principalmente - insisto - porque no fuimos preparados para vivirlo.

Es esencial encontrar la satisfacción personal en la experiencia vivida para que el ocio ocurra. Es necesario ocuparse libremente, por deseo, por satisfacción, por apreciación y por identificación. De acuerdo con Aquino y Martins (2007), el ocio integra la forma de ser de cada persona, siendo expresión de su propia identidad. Para ellos, el ocio no depende del tipo de actividad, ni del tiempo y ni del nivel económico. Sin embargo está relacionado con el sentido y la emoción atribuidos al momento experienciado. Para los autores, antes mencionados, es importante que diferenciemos el tiempo libre del ocio. Una actividad y el tiempo pueden no representar una experiencia de ocio, ya que el tiempo es una coordenada vital para los seres humanos y la experiencia del ocio - a través del enfoque psicológico - está definida como libertad de elección, que abarca una experiencia integral relacionada con el sentido de la vida, proporcionando al ser humano voluntad en vivir.

Es indispensable para el bienestar de los adultos mayores que el tiempo libre causado por la ausencia de trabajo encuentre el ocio. Es preciso el encuentro de sí mismo en el silencio para que llenen el vacío, para que se tornen conscientes de sus placeres, necesidades, sueños y metas. La experiencia del ocio humanista posibilita la potencialidad de encuentros creativos que llevan al desarrollo personal. Y aunque exista en el ser humano el miedo o la dificultad de encarar el silencio porque estamos acostumbrados a vivir en el ruido necesitamos recordar a los jubilados, y a nosotros 
mismos, que la calidad de vida no depende exclusivamente del trabajo. Hay otro ser que habita en nosotros. Además, somos personas, padres, amas de casa, ciudadanos, esposos, voluntarios, amigos, miembros de una iglesia, de un partido, etc., y eso es algo que perdura cuando uno deja de ser trabajador (CUENCA, p. 254).

\section{TALLER DE DOCUMENTACIÓN NARRATIVA DE EXPERIENCIAS PEDAGÓGICAS}

Todo comenzó con una llamada telefónica. Al principio no entendía lo que estaba escuchando, pero era lo que estaba esperando. (Docente jubilada de Quilmes). (información verbal).

Los talleres de documentación narrativa de experiencias pedagógicas de los docentes jubilados dieron inicio en Quilmes, el día 14 de Octubre de 2010. Fueron investigados diez docentes jubilados en dieciséis encuentros durante el período 20102011. Los docentes llegaron de libre y espontánea voluntad, a través de una invitación hecha por la municipalidad de la ciudad y por la Universidad de Buenos Aires. Sin muchas explicaciones, la invitación decía simplemente "su experiencia cuenta".

En el primer encuentro contamos con la presencia de veintiún docentes jubilados, posteriormente continuamos los talleres con diez docentes, quienes permanecen hasta hoy narrando sus experiencias pedagógicas. Los docentes jubilados de Quilmes narradores de experiencias pedagógicas decidieron escribir sus narrativas y entregarlas a nuestra sociedad por diversas razones: buscan hacer más por la educación, se sienten jóvenes, desean llenar el vacío de la jubilación, anhelan formar parte de un grupo, necesitan espacios de formación y reflexión, sienten falta de pertenecer al ámbito educacional, quieren ocupar la mente y el tiempo libre por sentir falta de una ocupación y/o les gustaría contar su historia para que quede registrada en la sociedad.

Los docentes investigados son maestros retirados de Matemática, de Lengua, de Historia y de Física; algunos fueron maestros de escuelas particulares y todos docentes de escuelas públicas. Algunos también directores o vice directores de escuelas y todos protagonistas del mundo escolar, con muchos años de experiencia profesional y muy enamorados de las Ciencias de la Educación y del arte de enseñar. Y principalmente, todos muy preparados para contar sus historias.

El objetivo de nuestros talleres fue la creación de un espacio para el rescate de la memoria pedagógica de los docentes jubilados, la apreciación de la importancia que tiene ese espacio en este período de la vida, la relación de este espacio con los sujetos colaboradores, la producción de las narrativas para ser llevadas a los institutos 
de formación docente y la observación de la relación entre el intercambio de las experiencias pedagógicas en distintas generaciones.

Los encuentros se realizaron no solamente con la esperanza de proporcionar nuevas enseñanzas a los docentes en formación, sino también con el deseo de que sirvan para estimular a los docentes jubilados a encontrar sentido en sus tiempos libres y a reposicionarse frente a una nueva realidad (ya fuera contando sus trayectorias, saliendo de casa, socializándose a través del grupo de docentes jubilados narradores, como también narrando sus experiencias, volviendo a las aulas, participando activamente de congresos, seminarios o ateneos, coordinando grupos o registrando sus experiencias en la sociedad).

Para tal, hicimos uso del método (auto) biográfico como metodología de investigación cualitativa, ya que nos ayudaba a rescatar las historias profesionales y de vida de los docentes jubilados. Fue, sin duda, una investigación formación-acción ya que la escucha de los relatos, producidos por docentes jubilados, ayudó a ellos y a la autora como docente-investigadora a encontrar su forma de ser docente, permitiéndoles una reflexión profunda sobre el mundo educativo, sobre su forma de administrar las clases y sobre la manera de observar a sus alumnos. En el escenario consciente o inconsciente de su memoria y de sus inquietudes aparece la comparación entre los métodos y las teorías pedagógicas usadas antes y los métodos y las teorías más modernas; la relación docente-alumno, alumno-escuela, docente-escuela, la currícula, la didáctica utilizada en el pasado y en el presente.

Además el dispositivo de documentación narrativa de experiencias pedagógicas (SUÁREZ, 2007, 2011) permitió rescatar la memoria de los docentes jubilados con el propósito de registrarla en nuestra sociedad, estimulándoles a escribir sus experiencias significativas a partir de talleres, discusiones, reflexiones y reescrituras de un mismo relato.

A partir del planteo de los objetivos general y específico surgió la necesidad de realizar un abordaje cualitativo a través de la documentación narrativa, la autobiografía y la investigación formación-acción. Se formó, así, un trípode digno de rescatar la memoria pedagógica, capaz de escuchar voces doblemente silenciadas, de estimular jubilados a hacer más, a buscar más, tornándolos escritores de sus historias. Es la presencia de ese trípode la que nos permitió la entrada en la historia de la educación, mostrándonos los saberes y los conocimientos generados cuando se vive durante más de treinta y cinco años en las aulas. Es por él y a través de él, que observamos a los docentes dar sentido a sus "valijas" de experiencias. 
Las lecturas y las escrituras de las narrativas acontecieron a través de reflexiones individuales y entre pares, siempre de forma horizontal y sin ningún tema puntual, las narrativas de los docentes fueron leídas para todos los participantes del grupo. La pregunta inicial para estimular la escritura fue “¿cómo llegué hasta aquí?”. A partir de ella empezamos a escuchar varios relatos. La lectura de cada uno de ellos estimulaba a los oyentes a preguntar, a indagar, invitándolos a compartir sus inquietudes de forma grupal. Esos pensamientos, conscientes e inconscientes, revelados o no, nos permitieron escribir nuevas versiones del mismo relato y también estimularon a los oyentes a escribir sus propias experiencias.

La tarea de escritura realizada en cada encuentro posibilitó a los docentes jubilados repensar sus historias, descubrir sus lugares en el mundo, transformar sus formas de ser/pensar. Un movimiento encantador y al mismo tiempo rico en reflexiones. La experiencia del otro afecta nuestras propias experiencias ya que cada narrativa leída genera un nuevo texto y se produjo así, en cada taller, un ciclo vicioso de escritura. Después de escribir distintas versiones de la misma experiencia y después de varias reflexiones, cuando finalmente el grupo y el propio escritor siente que el relato está concluido, la documentación a través de narrativas de experiencias pedagógicas les posibilita registrar la narrativa dentro de nuestra sociedad.

El registro a través de libros, revistas, ateneos, congresos, lecturas en institutos de formación docente e Internet, divulga y circula la experiencia profesional de los docentes jubilados; posibilitando a la sociedad ubicar y comprender las trayectorias de quienes enseñan y aprenden dentro de las instituciones de enseñanza, así como también permiten al docente jubilado reposicionar su saber experiencial, y lo ayudan a ser y a existir en el ocio.

Excelente la propuesta. Poder escribir las experiencias realiza-
das en el aula es maravilloso. Es dar continuidad a esta etapa de
desafíos, creatividad y búsqueda. (Docente jubilada de Quilmes)
Lo que hizo que viniera hoy ha sido mi necesidad de transmitir
a docentes jóvenes algunas experiencias positivas en mi carre-
ra. (Docente jubilada de Quilmes).
Escribir para compartir más allá de lo que pase con ese texto
me parece maravilloso. Tan fuerte es el vínculo que uno esta-
blece con el escrito y con el escribir con otros que estoy feliz
por haberme dado ese permiso. (Docente jubilada de Quilmes)
(informaciones verbales).

Gran parte de las inquietudes de la investigación pasaban por observar el recorrido del saber experiencial de los jubilados. ¿Para dónde va este saber?, ¿qué hacemos con él? ¿Qué espacios de ocios formativos tenemos en nuestra ciudad? ¿por qué muchos de esos espacios creados para los jubilados no rescatan lo que ellos ya 
vivieron, ya experienciaron, lo que ellos ya saben?, ¿por qué tengo siempre la idea de que los espacios abiertos en nuestra sociedad son la gran mayoría de las veces espacios recreativos de entretenimiento?, ¿será que repensar la propia vida y hacer uso de ese saber experiencial no es una forma de posibilitarles el ocio formativo?

Estamos haciendo cosas novas. (Docente jubilado de Quilmes). Llegamos a la conclusión de que escribir es una forma de dejar legado y poder transmitirlo. Abre espacios para un colectivo de discusiones. Hay momento para escribir, hay otros para escuchar y otros para discutir. La escritura trae la memoria al presente, la emoción, redefine nuestras experiencias, deja legado, nos hace reflexionar, escuchar y decidir ideológicamente lo que vamos a poner en el texto. (Docente jubilado de Quilmes).

En este grupo puedo desnudarme. (Docente jubilada de Quilmes).

Todas las veces que los escuché hablar del primer momento en que "disfrutan" de su jubilación viene a mi mente una escena en la cual está el jubilado, en su último día, saliendo de su lugar de trabajo con una valija llena de experiencia profesional. Lo observo desde lejos y lo veo cargarla con dificultad, ya que generalmente son muchos los momentos experienciados. Lo veo llegar a su casa y no encontrar espacio para depositar su valija de saberes. El jubilado es consciente de que en su hogar no hay un lugar ideal para guardarla. Pienso en él, reflexiono también sobre la sociedad y en los innumerables espacios donde guardar esas valijas de saberes y hacer usufructo de ellas. Desafortunadamente, estamos perdiendo el saber de la experiencia. Estamos rechazando sus "valijas". ¿Qué espacios son ofrecidos para que estas valijas sean "regaladas", "donadas", "abiertas" o "intercambiadas" con otros profesionales en actividad?, ¿podríamos generar profesionales más conscientes de sus prácticas si abriéramos espacios para las "valijas" de un jubilado?

\section{LOS DOCENTES JUBILADOS DE QUILMES Y EL OCIO FORMATIVO}

Durante los primeros talleres de documentación narrativa de experiencias pedagógicas, el grito de alegría, como etimología de la palabra “jubilación”, casi no estuvo presente en los diálogos. El ocio, la felicidad de tener su tiempo libre y el descanso, casi no fueron mencionados. Solo unos pocos estaban preparados para ese período de la vida. Las palabras dichas por ellos me parecían versos de oprimidos, de enojo y de insatisfacción. Comentarios esos que contestaron mis inquietudes iniciales. Palabras fuertes que confirmaban que el saber experiencial no ocupa espacio en nuestra sociedad, que muestran jubilados experimentados sin rumbo, perdidos, sin orien- 
tación ni planes futuros. Personas que extrañan las aulas, que no sentían necesidad de jubilarse. Docentes que temen la ociosidad y que no soportan el silencio y el vacío.

Me sentí muy vacío de expresión cuando me jubilé. (Docente jubilado)

Cada uno ha pasado y ha dejado una contraseña, me parece que tenemos que valorarlas. Acá pasamos todos como muy anónimos. Nuestra historia se queda en los alumnos que encontramos en las calles y que nos saludan. (Docente jubilado)

Uno se queda en silencio después. Lo que se queda es el silencio. Me siento sola sin el aula. (Docente jubilada). (informaciones verbales).

De los cuatro docentes hombres que estaban en nuestro taller, dos escribieron sobre el vacío que llega con la jubilación y los otros dos lo comentaron de forma oral en nuestro encuentro. Para Beauvior (1970), los hombres tienen mayor dificultad que las mujeres para relacionarse con el tiempo libre. Para muchos de ellos, la jubilación representa una pérdida de status social y utilidad. Ellos tienen más dificultad en ocupar nuevos espacios o buscar nuevas actividades durante esa nueva etapa de la vida. Además, presentan un riesgo más alto de depresión, vicios y/o suicidios que las mujeres.

Hasta que un día un silencio extremo [...] y repentino nos pone al borde de un precipicio haciéndonos trastabillar y sentir un vacío en el estómago y en el alma, vacilamos en el borde si nos hundimos en el abismo o comenzamos ahora a volar realmente [...]. (Docente jubilado) (información verbal).

Las mujeres jubiladas de hoy muchas veces encuentran espacio dentro de su propia casa. Muchas donan su tiempo libre para dedicarse a la familia y a los nietos, o buscan espacios placenteros y sin obligaciones laborales para permanecer activas. Cuando hay preparación para la jubilación se torna posible reinventarse u ocuparse con trabajos de casa. Apenas uno de entre los veintiún docentes de nuestro primer encuentro trajo en su narrativa la decisión y la preparación para la jubilación. De cierta forma, también aparece aquí la culpa que muchas mujeres cargan - principalmente las que hoy tienen más de 60 años - por haber dejado su hogar para salir a trabajar. Muchas lo hicieron, incluso, contra la voluntad de sus parejas y con el deseo de formarse y buscar independencia. Encontramos la culpa por su ausencia en la familia y los reclamos de su pareja e hijos. La jubilación, por su parte, trae la posibilidad de curar la culpa que llevan en sus "valijas". Es ahí que encuentran el sentido de la jubilación y en cierta forma, para ellas, es una manera de estar activas, de encontrar el placer y disfrutar del ocio formativo. 
Decidí, eso sí, comprometerme con mi hijo para cuidar a mi nieta durante los horarios en que tanto él como mi nuera coincidieran en trabajar fuera de su casa. Quería, fundamentalmente, disfrutar de su crecimiento y estar cerca para no perderme ningún cambio en su desarrollo y jugar todo el tiempo con ella, cosa que no había podido realizar con mis hijos [...] (Docente jubilada de Quilmes). (información verbal).

Sin embargo, a cada taller percibimos tonos de diálogos distintos. El repensar la propia vida les generaba y los genera hasta hoy empoderamiento. Durante los años de 2010 y 2011, el empoderamiento, la transformación y la co-formación de los sujetos investigados eran notables a cada taller. Para ejemplificar lo que digo cito a continuación parte de las narrativas de los docentes investigados en el tercer encuentro, donde reflexionaron, junto a los demás participantes, mostrándole que el vacío es algo que puede ser cambiado:

Para la filosofía oriental el vacío es muy importante porque permite llenar. Si algo está muy lleno, no entra más nada. (Docente jubilada de Quilmes).

Aprovechá el vacío, como hizo la profesora que leímos hace poco. (Docente jubilado de Quilmes).

No te aterrorices con el vacío. Confiáte. Hay vacíos que hacen bien. (Docente jubilada de Quilmes).

Ella cerró un capítulo de su vida, está llena de las vivencias que tuvo. Ella puede generar otras cosas. Para mí son ciclos que se van cumpliendo y se abren en otros. Eso es lo que tenemos que aprender. Aprender un idioma, un instrumento musical, estar con los nietos [...] La vida se transita por muchos ejes. (Docentes jubilados de Quilmes). (informaciones verbales).

Recupero también la trayectoria del coordinador del grupo actual, en su caminar por la documentación narrativa de experiencias pedagógicas. Él fue a nuestro primer encuentro y ya desde ese momento se comprometió a transmitir sus saberes e intercambiarlos con los docentes en formación. Desde el principio sentí que él había encontrado en los talleres un espacio que necesitaba para su jubilación. Allí, en nuestro grupo, empezó a sentirse activo de nuevo, útil, capaz y merecedor de esta experiencia. Nada lo desmotivaba a ir a nuestro encuentro: ni el mal funcionamiento del transporte público, ni la situación económica, ni la débil salud de él y de esposa, ni la distancia entre su casa y la municipalidad de Quilmes donde ocurría nuestros talleres.

Él no solamente fue sujeto colaborador de esta investigación doctoral sino que además volvió a ser estudiante. Empezó a estudiar teatro. Empezó a hacer natación. Sintió también necesidad de saber más sobre la documentación narrativa. Por lo tanto, decidió capacitarse en la Red de Formación Docente y Narrativas Pedagógicas para ser 
coordinador de talleres en esta temática. Participó de todos los encuentros de coordinadores y decidió llevar adelante, en 2012, el grupo de los docentes jubilados de Quilmes. Durante su coordinación alcanzó grandes progresos junto a ellos. Él llama y escribe semanalmente a los docentes jubilados como parte de su compromiso con los talleres. Varias son las narrativas de jubilados que él tiene en sus manos, varios son los institutos de formación docente que encontró como espacios de intercambio intergeneracional.

Más adelante, el docente decidió conocer más profundamente la epistemología de las narrativas (auto) biográficas y se anotó para participar del seminario de doctorado ofrecido por la Universidad de Buenos Aires. Sin embargo, también tenía sus miedos y sus dudas. ¿Ir a una clase de doctorado?, ¿pasar por las exigencias académicas cuando debería estar aprovechando el ocio? Una vez más, no hubo impedimento que lo detuviera: ni la distancia, ni la salud, ni la situación económica, ni siquiera sus miedos. Participó de todas las discusiones, se hizo presente en todas las clases, aprendió y puso en práctica sus aprendizajes en el grupo de docentes jubilados de Quilmes, cumplió con todas las obligaciones estudiantiles y se sintió orgulloso de entregar su monografía final.

El docente jubilado se reinventó a partir de los talleres de documentación narrativa de experiencias pedagógicas. Buscó nuevas formas de vivir, de experienciar el mundo. Buscó aprender y desaprender. Abrió espacios para la rememorización. Escribió varias narrativas que son leídas y comentadas en muchos institutos de formación docente de Buenos Aires. Encontró una nueva forma de ocupar su tiempo libre. Descubrió el ocio formativo. Se siente útil, es activo, encontró nuevos amigos, nuevas lecturas, nueva formas de ver el mundo y de ver a sí mismo. Está siempre buscando la lucidez al caminar por la vida. Se auto-forma, se trans-forma, se co-forma y deja legados en nuestra sociedad. El brillo en sus ojos y la felicidad en su voz al final de los intercambios intergeneracionales no serán jamás olvidados por los que lo escucharon narrar sus experiencias. El docente - aunque jubilado - ha encontrado formas de dejar legados y maneras de mejorar la educación de su país.

Soy un profesor jubilado de 67 años, egresado de esta Facultad hace mucho tiempo. Cuando, hace tres años, exactamente para el 14 de Octubre de 2010, fui invitado a una reunión de ex-docentes como yo, bajo el lema de La experiencia cuenta, o sea que se afirmaba que la experiencia puede tener sentido, nunca pensé que iba a transitar este camino tan largo y tan estimulante. Y, más aún, hace poco más de un mes, al decidir que iba a hacer este seminario de narrativa en la UBA [...], no tenía idea que eso que yo podría inicialmente ver como un trámite fatigoso iba a convertirse en algo tan importante en este momento de mi vida y que me iba a abrir tantos caminos como veo de ahora en adelante [...] (Docente jubilado de Quilmes) (información verbal). 
Sin dudas, Josso (2004) tiene la razón cuando nos dice que los talleres (auto) biográficos no son terapias, tampoco tienen objetivos de ser sesiones de psicoanálisis, pero sí son terapéuticos, si nos hace reflexionar nuestra práctica docente y nuestra práctica de ser humanos. El repensar la propia vida y la observación sí mismo en relación con el otro nos proporcionan experiencias formadoras.

\section{EL INTERCAMBIO DE EXPERIENCIAS INTERGENERACIONALES EN LOS INSTITUTOS DE FORMACIÓN DOCENTE}

"El espacio de intercambio estaba abierto para lo nuevo y lo viejo, el experimentado y el inexperimentado, los que salieron de las clases y los que estaban entrando en las escuelas. ¿Qué hablarían entre ellos?”, así empecé mi narrativa sobre el primer día de intercambio intergeneracional entre los docentes jubilados y los docentes en formación.

Los docentes jubilados, orgullosos de sus registros escritos y grabados en sus mentes, encontraron el sentido y la significancia en escribir las narrativas pedagógicas en ese espacio polifónico e intergeneracional. Volvían a las clases para contar algo de lo que habían vivido. Eran profesores una vez más. Los encuentros les otorgaba la oportunidad real de poder ver cambios en la educación. Era, quizás, en esos encuentros en que podían darse cuenta de lo importante que es mostrar para qué sirve una experiencia.

Las narrativas pedagógicas de los docentes jubilados eran leídas por cada autor. Los jóvenes prestaban atención, tomaban nota, lloraban y sonreían con las experiencias de los docentes. Parecían escuchar más atentamente que en cualquier otra clase, ya que eran experiencias reales y futuras que quizás tendrían que enfrentar alguna vez. La clase era muy significativa, tenía sentido escuchar cada palabra, tenía sentido sacarse todas las dudas.

Los textos escritos por los docentes en formación pueden decir más de lo que podría decir yo sobre el intercambio de experiencias. Creo que sus palabras fortifican los objetivos de la investigación. Además pienso que ellas dan significado al mundo de los docentes jubilados y al mundo de los jubilados en general. Una vez más, estoy segura de que si hubiese más espacios de intercambio de experiencias entre los jubilados y los profesionales en actividad (cualquiera sea esa profesión), menos silencio existiría en la jubilación, tendría más sentido estar vivos, los jóvenes tendrían más experiencias, la sociedad valorizaría más el saber y en las clases habría más profesores humanos. 
En los relatos escritos por los docentes en formación queda clara la necesidad de escuchar a los más experimentados, la voluntad de leer aún más narrativas y de acercarse de la realidad:

Con respecto a las charlas y narraciones que escuchamos, realmente fueron muy conmovedoras y movilizantes. Nos ayudan a ver la docencia desde otra perspectiva, como dijo uno de los profesores, "más humanizadora". Aunque nos hubiera gustado poder aprovechar más sus experiencias y escuchar otras. (Docente en formación) (información verbal).

Para ellos fue una forma de entrar en contacto con la realidad, con la práctica y con la experiencia vivida:

Somos cuatro compañeros que queremos agradecerles haber compartido algunas de sus experiencias docentes con nosotros. Al transitar este nuevo camino nos es muy útil y gratificante escuchar relatos reales, que tienen que ver con sus experiencias vividas y, por qué no, con nuestro futuro trabajo como docentes. Fue enriquecedor para nosotros el haber recibido y compartido vuestras experiencias y anécdotas, para poder sacar de ellas algún beneficio personal y así revertir algunas actitudes que consideramos impropias en el sistema educativo en el cual estamos inmersos. Muchas gracias. (Docente en formación). (información verbal).

Las experiencias vividas por los jubilados les sirven como "referencia" para sus prácticas, como un mapa, no para ser seguido, no para ser usado como guía, sino para mostrar los lugares por donde ya pasaron.

La charla que nos dieron fue muy productiva ya que muchos de nosotros podemos tomarlo como punto de referencia para nuestras prácticas y la experiencia en el aula. Todos nosotros estamos esperando el momento de entrar al aula por primera vez. Los relatos que ustedes nos leyeron nos acercaron más a la realidad conociendo diferentes enfoques. Nos resultó muy interesante escuchar los relatos que ustedes escribieron y en particular el que leyó el profesor de Matemática y Física porque a pesar de ser trágica, nos hizo reflexionar acerca de la importancia que tiene el profesor para el alumno. (Docente en formación) (información verbal).

Los docentes en formación que escribieron estos relatos comentaron también sobre los objetivos de la documentación narrativa: dejar legado, humanizar la tarea docente y humanizar profesores en formación. En sus palabras, las experiencias de los docentes jubilados “nutren” la formación de docentes jóvenes. Una vez más aparece la necesidad de escribir, leer y mostrar sus propias experiencias:

Hola. Su visita a nuestro establecimiento ha sido de mucha utilidad y muy interesante para nosotros, ya que como futuras 
docentes pudimos escuchar diferentes narraciones de experiencias pedagógicas que nutren las nuestras. Consideramos que el ejercicio de la documentación por escrito, que ustedes llevan a cabo con dedicación, servirá para perpetuar sus vivencias y humanizar tanto la tarea docente como nuestras observaciones pedagógicas como practicantes. Estamos dispuestas a intercambiar nuestras propias experiencias. Muchas gracias. (Docente en formación) (información verbal).

Ellos también hablan de emociones. Describen el intercambio como un encuentro emocionante, con narrativas que exprimen emociones y que conmueven. Nos muestran a través de sus escritas la decisión acertada y digna de ser docentes:

La visita de los docentes experimentados nos pareció una buena ocasión para reforzar nuestra decisión de estudiar un profesorado, ya que sus relatos nos conmovieron y además nos ayudaron a imaginarnos las diversas situaciones con las cuales nos podemos llegar a encontrar a la hora de entrar al aula. Nos pareció interesante la variedad de emociones que los relatos despertaron en nosotros: la risa, la sorpresa, la tristeza [...] Creemos que estos encuentros son muy interesantes y útiles para los aspirantes a profesores. Los esperamos próximamente. ¡Fue una clase muy emocionante! (Docente en formación) (información verbal).

Y, como en muchos de los relatos, los docentes en formación escribieron sobre la necesidad de recibir más visitas de los docentes jubilados para continuar aprendiendo a partir de sus experiencias, para continuar teniendo contacto con la realidad, con lo concreto y con la práctica y no solamente con la teoría y con el ideal:

Personalmente, creo que tanto la visita como los relatos fueron una experiencia enriquecedora, y sobre todo muy emotiva tanto para mí como para la mayoría de mis compañeros. Me aportó una nueva y distinta visión del rol docente, creo que tenemos una imagen de lo que deberíamos ser muy teórica e ideal, en cambio ellos nos mostraron un compromiso y actitud concreta y real que nos llegó y emocionó profundamente. Agradezco el nivel de compromiso mostrado a través de las experiencias vividas en dichos relatos y también por compartirlas con nosotros. Espero que estas visitas se repitan, ya que sus experiencias son útiles y enriquecedoras como referencia para jóvenes docentes. (Docente en formación). (información verbal).

Los docentes jubilados después de sus visitas a los institutos de formación docente volvieron a casa dejando parte de sus valijas de experiencia de vida, extremadamente felices y agradecidos por haber encontrado un espacio para ponerlas y personas para cuidarlas y sembrarlas. Están seguros de que sus valijas darán muchos más frutos estando ahí que en sus casas. A partir de los intercambios los docentes jubilados encon- 
traron el sentido, la significancia y la importancia de sus experiencias. No había más silencio en sus jubilaciones, sino felicidad, placer, reflexión, experiencia y ocio formativo.

Llevando las narrativas pedagógicas de los docentes jubilados de Quilmes a los institutos de formación docente, les mostramos la importancia de la documentación narrativa, la importancia del intercambio de experiencias y del vínculo intergeneracional. Al escuchar las experiencias de los jubilados, los más jóvenes fueron estimulados a contar y a escribir sus propias historias. La lectura de las narrativas les permitió reflexionar sobre su nueva profesión, sus nuevas miradas hacia la educación, sus nuevos riesgos, sus próximos desafíos. Les permitió ver la didáctica a partir de un nuevo ángulo. Es decir, se dieron cuenta de que vida, vínculo y contenido deben ser tres "herramientas" a poner en práctica en el aula. Comprendieron que se aprende significativamente cuando hay empatía, vida y sentido entre las cuatro paredes del aula. Tomaron conciencia de la importancia de repensar siempre su práctica. Con las narrativas pedagógicas de los docentes jubilados aprendieron a repensar las situaciones rutinarias de las clases y los desafíos docentes que pronto enfrentarán. Y al final de cada encuentro entre jubilados y aprendices en formación, vimos brillo en los ojos, abrazos apretados, admiración y mucho agradecimiento.

Los intercambios de experiencias docentes a través de la documentación narrativa entre docentes jubilados y docentes en formación hicieron posible una formación más humana, más práctica, más horizontal, más significativa, menos abstracta y menos teórica. Los docentes, desde ambos lugares, aprendieron a responder las siguientes preguntas: “¿cómo relacionarse con lo vivido y qué hacer con ello para que el saber de la experiencia pueda fructificar?, ¿cómo aprender de lo que nos pasa?” (CONTRERAS; FERRER, 2011, p. 27). Es decir, los docentes facilitadores de la enseñanza en los institutos, al abrir espacios para los docentes jubilados, demostraron la importancia de una didáctica vinculada a la experiencia, conectada a la búsqueda de un saber que se lleva puesto, un saber real y puro.

\section{CONSIDERACIONES FINALES: LA TRANS-FORMACIÓN Y LA CO-FORMACIÓN DE LOS JUBILADOS DE QUILMES A TRAVÉS DE LOS TALLERES DE DOCUMENTACIÓN NARRATIVA DE EXPERIENCIAS PEDAGÓGICAS}

Construimos un lugar para quienes creen, piensan y prueban que tienen historia; para los que sienten la necesidad de dejar un legado a los más jóvenes; para los que saben que ese legado puede ayudar a cambiar la educación de un país. Un espacio 
para los que no desean detenerse o jubilarse de la vida, para los que fueron echados por el sistema, para los que no olvidan sus guardapolvos y/o para los que sienten la necesidad de soltar la voz por los muchos años que pasaron callados. Un espacio sencillo, construido en cualquier rincón donde existiera el diálogo y el estímulo de la memoria a través del registro de narrativas pedagógicas.

Los docentes jubilados de Quilmes alcanzaron, de forma muy clara y obvia, un gran crecimiento en el plano subjetivo - referenciales teóricos y experienciales, valores y valorizaciones - y en plano psicosomático - sensibilidad, conciencia, memoria, intuición imaginación, creatividad, voluntad, emociones, pensamiento, intelecto (JOSSO, 2010).

Por lo tanto, como resultado de la investigación, testiguamos la auto-formación, la co-formación, la alter-formación, la trans-formación, la eco-formación y la con-formación del sujeto colaborador (los docentes jubilados de Quilmes). Es decir, a partir de la escritura de sus memorias, dejaron de ser solamente sujetos que pasan por la vida, salieron de la pasividad para tornarse activos, actuantes, conscientes de nuestra propia formación. En los talleres se forman "entre sí", entre la mirada del otro y nuestra propia mirada, lo que los lleva a conocer mejor el yo inconsciente, el yo escondido, el yo que no se daban cuenta de que permanecía en ellos, el otro yo. El yo que muchas veces aparece de forma inconsciente en el discurso o en la escritura y que les sorprende con su presencia a partir de la lectura o de los comentarios entre pares. A partir de ese movimiento, ellos se forman como sujetos plenos y conscientes de sus prácticas. La influencia del medio en que vivimos, del ambiente, del espacio ocupado, también les posibilita la recreación del yo (PINEAU, 2010). La con-formación fue posible con la ayuda de la Red de Formación Docente y Narrativas Pedagógicas.

Vimos nacer un yo involucrado, participativo, consciente, reflexivo, narrador y contador de historias. El vacío - tan comentado por los docentes jubilados - que provocaba la jubilación se llenó de ruidos, de voces, de actividades, de nuevos pensamientos, de nuevos amigos, de nuevas conquistas y del ocio formativo. El rol docente, las aulas, las clases que tanto extrañaban estuvieron siempre presentes en la escritura, en los diálogos y durante los encuentros en los institutos de formación docente. Los alumnos fueron sustituidos por aprendices/observadores de sus experiencias. Cualquier docente joven que se mostraba interesado en sus historias les causaba sensación de bienestar, era como poder ser docente de nuevo, lo que a su vez les provocaba sensación de capacidad, utilidad, felicidad y autonomía. El sistema, que les había traído silencio y afonía, ahora era muy bien criticado, muy bien evaluado por los docentes, que se sienten libres para poder decir lo que piensan y libres para poder hacer más por 
el mundo educativo. El reconocimiento por el trabajo bien hecho - que fue tan comentado, necesitado y buscado en muchos de sus discursos y narrativas -, ahora no venía solamente de los alumnos que los saludaban en las calles. El reconocimiento venía de cada lectura hecha de sus narrativas, de cada lector que lee sus experiencias, de cada docente joven que los escucha, de cada profesional que se prepara para la jubilación y de investigadores que se adentraron en sus vidas.

El tiempo libre y las vacaciones largas recibieron otros nombres, ahora eran llamados ocio formativo y de cre-(a)activ-edad. Los sujetos colaboradores de esta investigación descubrieron que la jubilación les permite crear-se, inventar-se, rescatando lo que uno fue, era y es. Los talleres les permitieron ser activos, productivos, y la jubilación fue aprovechada para hacer lo que postergaron durante los años de trabajo: repensar su praxis, sus experiencias, transmitir y dialogar sobre/con su saber experiencial.

\section{REFERENCIAS}

ALLIAUD, A. Los maestros y sus obras. Revista Educación y Pedagogía, Medellín, v. 23, n. 61, p. 81-92, sep./dic. 2011.

ANDERSON, G. El docente-investigador: investigación-acción como una forma válida de conocimientos. In: SVERDLICK, I. (Comp.). La investigación educativa: Una herramienta de conocimiento y acción. Buenos Aires: Novedades Educativas, 2007 p. 1-21.

ANDERSON, G.; HERR, K.; NIHLEN, A. S. Studying your own school. An Educator's guide to Practitioner Action Research. California: Corwin Press, 2007.

AQUINO, C. A. B.; MARTINS, J. C. O. Ócio, lazer e tempo livre na sociedade do consumo e do trabalho. Revista mal-estar e subjetividade, Fortaleza, n. 2, p. 479500, set. 2007.

BAKHTIN, M. Estética da criação verbal. São Paulo: Martins Fontes, 1992. BEAUVOIR, S. La vejez. Buenos Aires: Sudamericana, 1970.

BENJAMIN, W. El narrador. In: BENJAMIN, W. Iluminaciones IV. Para una crítica de la violencia y otros ensayos. Traducción Roberto Blatt. Madrid: Taurus, 1998. p. 29.

BOLÍVAR, A.; DOMINGO, J.; FERNÁNDEZ, M. La Investigación Biográfico-Narrativa en Educación: enfoque y metodología. Madrid: La Muralla, 2001. 
BOSI, E. Memória e sociedade: lembranças de velhos. 4. ed. São Paulo: Companhia das letras, 1994.

CUENCA, M. C. Ocio humanista: dimensiones y manifestaciones actuales del ocio. Bilbao: Instituto de Estudios de Ocio de Universidad de Deusto, 2000. Documentos de Estudios de Ocio número16.

CUENCA, M.C. Aproximación Multidisciplinar a los estudios de ocio. Bilbao: Instituto de Estudios de Ocio de Universidad de Deusto, 2000. Documentos de Estudios de Ocio número 31.

CONTRERAS, J. D.; FERRER, N. P. L. Investigar la experiencia educativa. Barcelona: Morata, 2010.

DELORY-MOMBERGER, C. Biografia e educação: figuras do indivíduo-projeto. Natal: EDUFRN; São Paulo: Paulus, 2008.

FREIRE, P. Pedagogia da Autonomia: saberes necessários à prática educativa. São Paulo, Paz e Terra, 1996.

FREIRE, P. Pedagogia do Oprimido. Rio de Janeiro: Paz e Terra, 1970.

JOSSO, M. C. Experiências de vida e formação. São Paulo: Cortez, 2004.

JOSSO, M. C. Caminhar para si. Porto Alegre: EDIPUCRS, 2010.

LARROSA, J. Tecnologías del yo y educación: notas sobre la construcción y la mediación pedagógica de la experiencia de sí. In: LARROSA, J. (Ed.). Escuela, poder y subjetivación. Madrid: La piqueta, 1995. p. 257-361.

LARROSA, J. Notas sobre a Experiência e o saber de Experiência. Revista Brasileira de Educação, Rio de Janeiro, n. 19, p. 20-28, jan/abr. 2002.

NULAND, S. B. A arte de envelhecer. Rio de Janeiro: Objetiva, 2007.

OLINDA, E. M. B.; CAVALCANTE, F.S. JUNIOR. (Org.). Artes do Existir: trajetórias de vida e formação. Fortaleza: Edições UFC, 2008.

PASSEGGI, M.; ARAUJO, M. Processo de biografização em contexto institucional. In: SOUZA, E. C.; PASSEGGI, M. C.; VICENTINI, P. P. (Org.). Pesquisa (Auto) biográfica: trajetórias de formação e profissionalização. Curitiba: CRV, 2013. p. 139-156. 
PASSEGGI, M. C.; SILVA, V. Invenções de vidas, compreensão de itinerários e alternativas de formação. São Paulo: Cultura Acadêmica, 2010.

PASSEGGI, M.C. Narrativas Autobiográficas: solidaridad y ética en educación. Rhizome freirean, n. 11, 2011. Disponível em: < http://www.rizoma-freireano.org/ index.php/narrativas-autobiograficas-solidariedade-e-etica-em-educacao-maria-da-conceicao-passeggi>. Acesso em: 15 sep. 2013.

PINEAU, G. A autoformação no decurso da vida: entreo hetero e a ecoformação. In: NÓVOA, António; FINGER, Mathias (Org.). O Método (auto)biográfico e Formação. Natal, RN: EDUFRN; São Paulo: Paulus, 2010. p. 97-118.

PINEAU, G. As histórias de vida em formação: gênese de uma corrente de pesquisa-ação-formação existencial. Educação e Pesquisa, São Paulo, v. 32, n. 2, p. 329343, maio/ago. 2006.

RICOEUR, P. La memoria, la historia, el olvido. Buenos Aires: Fondo de Cultura Económica, 2013.

RICOEUR, P. Tiempo y narración. México: Siglo Veintiuno Editores, 1995.

SOUZA, E. C. O conhecimento de si: estágio e narrativas de formação de Professores. Rio de Janeiro: DP\&A; Salvador: UNEB, 2006.

SUÁREZ, D. El saber de la experiencia: maestros, narrativas y nuevas perspectivas para la formación docente continúa. In: POLO, P.; VERGER, A. (Comp.). Globalización y desigualdades educativas. Palma de Mallorca: Escola de Formación en Mitjans Didàctics, 2007. p. 184-198.

SUÁREZ, D. Narrativas, autobiografías y formación: una presentación y algunos comentarios. Revista Educación y Pedagogía. Medellín, v. 23, n. 61, p. 11-22, set./ dez. 2011.

VON FRANZ, M.; BOA, F. O caminho dos sonhos. São Paulo: Cultrix, 1988.

WILDE, O. O Retrato de Dorian Gray. Rio de Janeiro: Civilização Brasileira, 2000 .

Recebido em: 11 de outubro de 2015 Aceito em: 22 de fevereiro de 2016

Endereço para correspondência: Viamonte 430, 1053, Buenos Aires, Argentina, palermo.danisegg@gmail.com. 
